\title{
Stuck in a Moral Prison: Exploring the Roots of Why Indonesian Students Moralize Literature
}

\author{
Danielle E. Donelson-Sims \\ Satya Wacana Christian University, Salatiga, INDONESIA \\ email: danielle.donelsonsims@gmail.com
}

\begin{abstract}
This paper explores a belief in Indonesian culture, held by educators and students, that literature teaches morals. While learning literature offers a potential benefit, a problem arises when instilling and/or recycling moral knowledge is recognized as the only reason to learn literature. When identifying established morals becomes the stopping point, other elements may be ignored, such as critical thinking, culture, history, perspectives, and marginalization. Four literature lecturers and seven students were interviewed. Data revealed all participants had varying definitions of "morals," leading to potential classroom confusion. All participants agreed morals ought to be considered, but only the (majority of) students identified them as the most important in literary study. Additionally, not all students enjoyed finding morals; some were rather bored by examining morals. Lastly, most participants believed Indonesian culture and education contributes to the habit of searching for morals, and valuing them at the expense of other learning benefits.
\end{abstract}

Keywords: Morals, literature, EFL classroom, teaching, class discussion

\section{INTRODUCTION}

As teachers, we all have our little pet peeves, little things that students do, write or say that irk us. Perhaps these aggravations do not irritate our colleagues as they do us. Maybe fellow peers would even fail to notice these habits, but would cringe at something else. Pet peeves are subjective, and largely reflect our individual values and priorities. Though a part of human nature, these moments of irritation are not teachers' proudest moments. However, if we, as educators, are entirely honest with ourselves and with each other, most of us could identify a student practice or habit that just simply, perhaps irrationally, annoys us.

Moving to Indonesia and teaching Introductory Literature classes at Satya Wacana Christian University helped me to pinpoint mine: when a(ny) literary work is reduced to simplistic moral lesson(s). I found my heightened sensitivity to this surprising. Previously, I had taught English 101 and 102 in American colleges and universities, and I was never bothered by students concluding their essays with a cliché, naive idealism, or overused, tired language. While my peers grumbled, I would inwardly chuckle, not understanding my colleague's frustrations. Consequently, my own annoyance at EFL Indonesian students' frequent comments on 'the moral of the story" puzzled me; I was unaware that something as seemingly benign like virtues could disturb me so. Why did waves of irritation stir within me whenever the class ceased forward movement or further discussion, after "the moral" had been discovered? In those moments, feeling peeved and noticing my students' confusion at what else, what more, I could possibly want from them, I realized: this pet peeve is worthy of further analysis and self-reflection.

As time went on, this moralizing happened frequently and the situation grew more puzzling still: despite texts presenting moral ambiguity, students would often manipulate, and even alter details to arrive at a conclusion of how they ought or ought not to live. These desperate pursuits to gain some virtue from literature were as foreign to me as the Indonesian language and culture I struggled to learn. Searching for a moral from fictional works was not a part of my high school, college or university level literature classes. In fact, not since elementary school (through folk tales, tall tales, and nursery rhymes) do I ever recall paralleling literature with moralism. I began to wonder if perhaps Indonesian culture and/or my students' educational backgrounds played a part in why this was happening.

My puzzlement and irritation grew, to the point where I would breathe relief after my students finished the 
moral discussion. Ironically, my most energizing moments came after this obligatory lesson; I would grow excited, eager to get on with it, to move forward to more insightful discussion, where we could discuss the gray, and the lovely abstract that literature so often explores. My positive moment came at precisely the same time when many of my students had disengaged and mentally checked out from active class participation. Our dissimilar focuses and polar opposite priorities rendered the situation almost laughable, if I had not found it so frustrating. So I began this research, seeking to understand: why do so many Indonesian students in introductory literature courses avidly search for (and often only for) morals? Once this moral is found, do they cease thinking or further discussing - seeming to imply that nothing more, at least of any substantial worth, can be gained from literature discussions? Furthermore, if this mindset holds true, then why?

\section{MORALS IN LITERATURE}

The belief that literature can be used to instill morals and build character is not a new concept. As early as Ancient Greece, Plato (2008) in his famous piece, the Republic claimed that if arts (and by extension, literature) do not teach morals and ethics then such art damages people, or the republic. His extreme statement, now recognized as one of the first pieces of literary criticism, is still used by philosophers, critics, and educators as they consider the purpose(s) behind teaching literature, and question the (potentially negative) effects art can have on society.

Many centuries later, teaching morals through literature still surfaces as a frequent topic of academic discussion. Those who weigh in on the issue of moralizing literature do not stem from one discipline, quite the contrary. Literary, film and art critics, philosophers, moralists, educators, sociologists and more, all explore the issue of moralizing arts. The reason is clear: morals represent a defining part of our lives; therefore, it only makes sense that discussions of morals and ethics penetrate the fluid borders of disciplines, emerging as a topic in many academic circles.

Though a frequently talked-about topic, many writers maintain different stances on the issue of moralizing literature. Some echo Plato and argue that the entire value of a piece of literature lies in its lessons or instilling certain values. Kirk (1981) held this view, in stating that "great books do influence for the better, and bad books do drag down the general level of personal and social conduct" (p. 37). While his argument makes sense logically, it leads to many other complicating factors. Morals are inherently subjective and evaluating art on the grounds of morally good or morally bad books brings forth other questions such as: Can texts that portray any immorality pass this "morality test?" If so, how and what measurement ought to be used? Or, must evil never prevail within a story; otherwise, a story stands as grounds for immorality? If a character acts immorally then learns from his/her mistakes, can such a work be deemed morally acceptable? Or, perhaps does the morality rest within the emotion and virtue of the reader, not from the character(s)?

While challenging questions of moralism do not always provide easy answers, many critics argue this does not present just cause to entirely eliminate discussion of morals in literature. On the contrary, some writers find the very notion diminishing to the power of literature as literary arts have a unique and powerful ability to engage and change us as human beings. Taylor (1995) contended that "literature is inescapably tied to ethics and is useful in personal ethical development, thought, and action" (p. 58). In teaching us how to live, Taylor (1995) proceeded to argue that "[s]tories abound with questions of "ought", and are therefore a "powerful if imprecise embodiment of humankind's preoccupation with right and wrong" (p. 58). As literature so obviously connects life and morals, ethical concerns must not be left out of the literary discussion, even when and if "ethical matters do not always allow for easy solutions" (Bonadanna, 1999, p. 1).

Pantic (2006) also recognized the value of art to teach morals, in stating that, "books and literature can teach us something about ethics and the human condition in its intimate and universal aspects, as well as illustrate the follies and achievements of our own epoch" (p. 401). She further argued that it would be difficult to deny or ignore the fact that literary works plays a role in "sharping and cultivating our cultural, aesthetic, and moral senses" (p. 402). Carroll (2002) agreed, as he stated that "literature and art can function in the service of knowledge and education" bringing about "enlightenment" from "moral, psychological and social knowledge" (p. 3). Carroll (2002) further argued that art "can function and is designed to function as a source of moral knowledge" (p. 4).

Though literary study may function as a means to uncover morals, such practices are not always done well. Too often educators approach teaching morals through literature in a way that amounts to "little more than truisms" (Carroll, 2002, p. 4). If literature selections deal with general truths that are already known and accepted by readers, even Carroll (2002) 
conceded, that said literature "teaches no one anything" and does "not produce new knowledge" or help readers to "make new discoveries" (p. 4). In these frequent cases, literature study is used in order to "recycle truisms that readers already know" (p. 4). Literary discussions may focus on morals, a commonly accepted plus point, but common knowledge may be revisited, rather than focused on learning new lessons.

Furthermore, while many major figures hold the belief that literary works may serve to aid in moral education, the more pertinent question remains: how? Even if instilling morals is deemed productive or worthy endeavor, such indoctrinating cannot occur if students are not open to emotion and feeling (Crary, 2000; Jenkins, 1997). Drawing from Aristotle's writings, Crary (2000) contended that "feeling plays an essential role in moral understanding" (p. 315). Therefore, the effort of building morals and character is rendered futile if students do not act as active affective participants, which is difficult to guarantee.

Perhaps these potential problem areas in discussing morals are what cause some, myself included, to "bristle at the notion that literature 'inculcates' virtue" (Carroll, 2002, p. 3). For even supporters of the notion that literature can teach values recognize its downfall. Murdock and Posner pointed out how moral judgments derived from literary pieces can appear "crude or overly facile" (as cited in Bonadanna, 1999, p. 1). Bonadanna (1999) also recognized this problem, advising readers to avoid moralistic judgments which are "crude, overlyjudgmental, or over-simple" (p. 1). However, he clarified that when ethical questions are explored and considered, readers may avoid "prescriptive rule" and "learn that some ethical questions are dilemmas that allow no easy solutions" (p. 1).

The notion of art as inherently moral or immoral also changed as a result of twentieth-century literary criticism; modern theories challenged ways of knowing, questioned reliability, and posited that matters of subjectivity, perception, and biases must always be considered. Modern post-structuralists have become highly suspicious of morals, even questioning if moralism can exist, given the "cultural relativity of morality" (Pantic, 2006, p. 402). Recent criticism also resulted in a dramatic increase of questioning, and even mistrusting, narrators or speakers, authors, and characters. Ricoeur (1970) has even identified recent phenomenon as creating a "hermeneutics of suspicion," one that encourages readers to become overly skeptical to a dangerous and unproductive point, when suddenly no one and nothing appears trustworthy (as quoted in Josselson, 2004, p. 1). As modern literary theories have developed, attempting to uncover implicit and hidden themes, literary critics have shifted focuses away from teaching moral. Though perhaps less emphasized in literature academe, the issue of moralizing arts has not yet been entirely lost, either within specific academic sectors or within tertiary level literature classrooms in Indonesia.

\section{METHODOLOGY}

In both seeking to understand this cultural phenolmenon and self-discover the roots of my own frustrations in moralizing literature, the idea for this research was born. Seven students and four literature lecturers were interviewed about their perspective on the importance of morals within literature. The student participants were lower level students who have not taken higher level literature classes; consequently, the majority of their instruction in how to study and analyze literature derives from their previous educational experience, prior to enrolling in university. The lecturer participants were selected because of their literature expertise and experience teaching lower level literature classes. Although listening to viewpoints obviously does not guarantee us universal truths or objectivity, they can and perhaps should be used as a first step in approaching a less explored issue (Cresswell, 2007).

The interviews were recorded and loosely structured; open-ended questions as well as follow-up questions were used to allow for optimal flexibility with opportunities to clarify and re-check and re-confirm information. The interviews employed code-switching methods; so both English and Indonesian were used, as per the participants' preference. I reassured the students that I would adjust minor grammatical or lexical errors in the transcription process. I stated this to help participants to focus more on the content of the answers rather than their grammar or language. I tried to allay any concerns about "improper" English or minor errors, as language was not the topic of research; rather, their experiences, perspectives and opinions were considered of primary importance.

Additionally, the interviewees' identities will remain anonymous in the discussion of my findings. According to Weis and Fine (as quoted in Cresswell, 2007), this is a purposeful decision, recognizing that the findings and conclusions may have direct and/or unintended effects on the participants. After the data had been collected, I read and color-coded emergent, reappearing themes in my transcriptions so as to identify "salient themes, recurring ideas... or patterns of belief' (Marshall \& Rossman, 2006, p. 158). From the above coding process the following five distinct themes emerged. 


\section{EMERGENT THEMES}

\section{Ambiguity in the term "Moral"}

The first theme that emerged was the inherently ambiguous definition of morals. The dual definition of the word moral creates confusion among native speakers of English, when language and cultural barriers may not interfere with comprehension. According to the Oxford English Dictionary (n.d.), morals may be "a lesson that can be derived from a story or experience," or they may indicate "standards of behavior; principles of right or wrong." As both definitions bear similarities and are commonly used, in similar contexts, it stands to reason that a speaker could use the term "moral" and be misunderstood by a listener, and yet the issue remains unnoticed and unquestioned. A speaker could refer to one definition, while the listener understands the word to indicate another definition. Certainly, a misinterpretation of this word could pose problems, specifically in a foreign language learning environment.

A parallel can be drawn to the Indonesian language. The word in Bahasa Indonesia for moral, "nilai," also allows for potential confusion, as the definitions mirror those in English. According to Kamus Bahasa Indonesia Online (n.d.), "nilai" may refer to a value; something of importance or of use to humankind; something closely related to ethics. Consequently, "nilai" has various definitions and could present potential misunderstandings in Bahasa Indonesia, as it does in the English language.

To try and better understand my participants' understanding of "morals," I asked them to define the word, based on their understanding, hoping to employ his/her understanding of the word rather than projecting my own. Of my student participants, all held varying ideas of the definition of morals. Two participants used a dichotomy to articulate their understanding of a moral. One participant defined the word "something good or bad;" while the other contended that "a moral is a value that is from a positive or negative side of humankind," again offering a binary. However, two other participants posed much more general ideas: one stated that a moral is "a positive point" from the story, while another simply claimed that it is "what we get" from a work. Therefore, some understand morals in terms of the value, either positive or negative, while others held to a more general idea.

Perhaps not surprisingly, lecturers provided more rich and detailed understandings of morals. One participant pointed out that morals are closely connected to "our relationship with God"; she also contended that they "cannot be separated from the way we are raised" as well as "from our own experience." Another lecturer more generally understood morals to be synonymous with "value", while another believed morals to mean "a message" that is more abstract and allowing for gray area. Similarly, another lecturer understood morals to be "very subjective and relative", the latter two offering contrasting views to the dichotomies provided by two student participants.

My point in extensively discussing the variation in definitions is to illustrate how easily miscommunication could result from the seemingly benign assumption that we all understand and accept the same meaning of morals. It stands to reason that the very definition(s) could pose confusion and lack of clarity, even before more challenging elements, such as story themes, new vocabulary, idioms, and foreign cultural information, were discussed. A literature lecturer may hold different ideas of what constitutes a "moral" from what his/her students understand the word to mean; therefore, rather than assume that teacher and students agree on a definition (of "moral" in English or "nilai" in Bahasa Indonesia), further clarification may help to aid in-class discussion and limit further misunderstandings, because, as previously mentioned, even speakers of the same level of education and culture do not always hold similar viewpoints of what moral means. Furthermore, depending on the context, the definition may change.

\section{Perceived Importance of Discussing Morals in Literature}

As previously stated, through my teaching experiences, students frequently discuss and write of the importance of morals in literature. However, rather than assume all share the same opinion, I asked the participants if they saw morals as an indispensable part of studying and understanding literature.

In response to my question, one student said: "With [sic] learning literature, we should know what the moral value is. If we read something we should find what the moral value is". This student further explained that "With $[s i c]$ learning morals, I can learn what the meaning of literature itself is". These students' rhetorical choices indicate that they understood learning literature and morals to be closely connected. Furthermore, the statements reveal the assumption that whatever literary work is read has a moral statement and such a moral needs to be found.

Another student participant stated, "It's always in education to look for the moral value after reading a story". She further commented that this was true 
regardless of the specific language being studied. Additionally, a fellow student stated that a "moral is the goal for any works". Therefore, this student saw the "moral as the most important part of the work itself".

The remaining students admitted that they had initially believed morals to be the main point of studying literature. However, their instruction in university classes had altered their opinion and expanded their perspective on this issue. Consequently, the remaining participants' responses mirrored closely a lecture I had given in the Introduction to Literature class, cautioning against only searching for morals in studying literature. Since their responses resembled by own opinion, I focused only on the ones above.

\section{The search for Morals: Enjoyable or Not?}

After hearing that many students view morals as significant to understanding literature, I asked them whether discovery of a moral serves as an acceptable stopping point. In other words, do they continue thinking more about a literature work if they have already discovered the moral? In response to this question, one student stated, "If the moral is the positive value, then I just stop" (in reference to thinking about the literary work any further). She also added, "Because that's it. That's just all". Her friend commented that, after finding the moral, "We have got the point. What else to be taught?"'

While I felt disheartened at the limitations they put on the value of literature, and saddened by the other benefits they were losing out on, their responses confirmed my previous experiences. Furthermore, they indicated I had not misread previous students' actions or lack thereof. The three lecturer participants admitted to having experienced the same teaching struggles that I have: often times lower level literature students would jump right to finding and discussing the moral in their journals or in class discussions.

\section{Morals: Boring or Stimulating to Students?}

One part of my interview specifically asked whether students enjoyed searching for and discussing virtues from literature texts. I admit my bias here: if, in my educational background, morals were taught as synonymous with literature, I am confident I would not have pursued the discipline for my graduate study. Therefore, I sought to understand if students enjoyed this pursuit of virtue lessons, or if they felt obliged to do so.

One student interviewee claimed that, "Sometimes I just want to read for free. I don't want to think about the moral. Moral is some plus point, but sometimes when I feel stressed out" or "when I'm not in the mood, I will read for fun". Although this participant did not directly admit she does not enjoy looking for morals, her response clearly indicates that searching for morals is not something always or consistently fun. As such, we may conclude that "free reading" that is "for fun" does not always require looking for a moral.

Another student candidly admitted, "Honestly, morals were fun to be learned when I was a child. When I'm growing older, I found that I already know many things about positive values. So now that I'm 20 years old...it's a little boring for me." This students' statement echoes Carroll's (2002) concern. He asserted that this problem all too frequently occurs in literature classes: when the truths meant to be taught are "a trivial sort with which audiences are long familiar" (p. 4).

One participant claimed that "if in every story, I have to find the moral, one by one, I think it wastes my time". Interestingly, the student claimed that searching for a moral is "like new knowledge," that it "can add to our knowledge" and "make us wiser". Despite knowing these supposed benefits of morals, she still admitted to her own lack of interest in always searching for morals. Rather, her rhetorical response appears to indicate that morals are healthy for her and a practice that she ought to do, rather being a practice she actually enjoys.

Carroll (2002) warned of the dangers in requiring students to regurgitate knowledge that does not teach new material. He argued that when "the knowledge is so familiar" then "no one is ready to appreciate the art in question" (p. 4). While aesthetic appreciation is certainly a concern, I would argue that, even worse, students may end up repelled by literature. Such occurrences would be a true shame, for literature offers a great deal more to students than didactic lessons. However, if students' hold to this perception and are not challenged to think of literature as otherwise beneficial, then other values may not matter or make much of a difference.

\section{Indonesian Cultural Influence}

Lastly, I asked participants whether they saw their previous educational background and/or culture as playing influential role(s) in this matter: why are morals and literature so closely connected?

All but one participant identified culture and cultural stories as a contributing factor to this situation. One 
student commented that, "literature can be a medium to record those moral values that exist in our culture". He further explained that, "There are so many old stories, especially in Java, that contain good morals to build characters". He further commented that "each one is about learning morals". Another student gave a similar response, "Indonesians have folk storiesthey will always look for and ask for the moral. We always look for the moral values. It's a habit".

A lecturer participant agreed that culture may be a contributing factor, in commenting that "our society and culture pays attention to how someone should behave". She further added that Central Javanese people "pay much attention to social harmony and good behavior". This perhaps "is why we pay attention to morals". A student participant echoed the teacher's statement in saying that, "All the morals is a must - agreement. You have to obey. It's the culture". Another lecturer stated that "the moral standard parameter" becomes "the only parameter to judge everything". Though the lecturer admitted she found this difficult to understand and to connect, it was seen as a common view in her opinion. She further commented that "perhaps hierarchy and authority" can be considered as a possible reason why so many cling to ideas of morals. She added, "Perhaps parents and authorities who make decisions influence the idea that everything should be moral."

Lastly, one lecturer claimed that "the Authorities," or those in a position of higher status, such as parents, educators and other teachers, may have perpetuated the idea of moralizing literature, and demonstrated it through previous educational and reading experiences. One student participant stated that her past education "emphasized more on the moral of the ending". She further added, "Since we were younger, we have been taught that. And so it stuck with us."

Perhaps some readers may question whether the participants' views reveal a cultural distinction. However, the reflections shared above are based on the students' and lecturers' own answers to the question of how this matter of moralizing may be related to their cultural context.

\section{IMPLICATIONS FOR THE CLASSROOM}

Is moralizing literature wrong? Absolutely not. Despite my initial irritations, I do recognize that discovering moral values in literature may be one great benefit literature has to offer humanity. However, moralizing becomes a problem when we perpetuate the myth that moral lessons represent all that literature has to offer, or the notion that revisiting accepted virtues is productive, interesting, or important for classroom discussions.

Some literature lecturers may be wondering: what then is a proper way to engage in a discussion about morals? Taylor (1995) offered an idea of looking at morals through ethical discussions, which seek to preserve "human experience for contemplation and evaluation". In Carroll's (2002) idea of evaluation, we may envision this process as more holistic and nuanced than dismissive labels of black or white, or absolutist categories of moral versus immoral. Likewise, we ought to encourage discussions that delve deeper and either "dispute" or "supplement" ethics with "further argumentation and analysis" ( $p$. 6). Argumentation and analysis imply discussion and critical, not reductive, thinking. Perhaps such in-depth discussion has been lacking in high school literature classrooms, as students believed their high school experiences demanded agreement with the teacher and the right multiple choice answer over a critical thinking process. Furthermore, as suggested by my interviews, less challenging literature may be why the subject becomes boring, especially if students are only familiar with literature as a reexamination of overly simplistic moral lessons.

In considering how to produce fruitful class discussions about morals, we could perhaps employ Sorenson's idea, and regard the class discussion as a thought experiment that purports "to deal with questions by contemplation (as cited in Carroll, 2002, p. 7). Sorenson advocated using process, to take the time to consider aspects of "the design" rather than "the execution." At the same time, Carroll (2002) encouraged us to work towards reaching "empirical discoveries" and "conceptual refinements" (p. 6). When used correctly, such discussions can "clarify linkages between parts of our cognitive maps" (p. 8). In this way, students may learn new information rather than simply be made to recite stored knowledge.

Some educators may argue that given EFL students' limited language skills at the Introduction to Literature level, these types of in-depth discussions may be difficult to encourage, generate and sustain. As English is often encouraged as a medium of communication when students enroll in a college English program, this does not mean that codeswitching methods must be entirely dismissed or forbidden. On the contrary, sometimes code-switching is necessary and it allows for increased selfawareness of unfamiliar words, which could invigorate EFL learners to engage in active vocabulary-building and discussion of new concepts. 
Though challenging, such circumstances may act to stimulate students and encourage them to acquire new words even from each other; as in my experience students will supply words for their peers when they falter in their English. Additionally, an analytical discussion on morals or ethical debate may be a more appropriate final assignment or a goal for higher level classes, clearly not suitable for a beginning assignment in an introductory EFL literature class. Still, this activity or approach ought not to be entirely dismissed because of a possibly challenging nature.

I would caution educators that if EFL learners in literature classes remain unchallenged to expand and develop, both in critical thinking and in language, negative effects may result. It is possible that students will plateau, ceasing further development. Though EFL learners may be at a lower English language level, as my participant pointed out, they are adults, and as such may appreciate readings that do not cover elementary moral lessons. Likewise, they may thrive on adult discussions that, while challenging, do not encourage didactic lessons but explore complex real life issues. By presenting more morally ambiguous works or ones with complicating, destabilizing factors, we may pique students' interest, while at the same time showing we value their adult perspectives, as we all weigh ethics issues together.

Wiggins (2011) realized this lesson from her teaching experiences; she learned to not try and "inculcate" her students with her own morals while teaching literature. Instead, she emphasized the process through which students learned about ethics, namely through Socratic seminar, which allowed her students to engage and draw their own conclusions about ethics. In stepping back and limiting her own voice, while requiring her students to cooperate as their assessment was not based on individual efforts, her students collaboratively debated about ethical conducts. In this way, ethics became a topic of discussion that emerged from literary works. However, simply restating established virtues as undisputable truths was unacceptable. Rather, the class activity (and the students' grades) demanded they actively engage in discussing and weighing ethical questions from the text, not accepting one blanket solution.

Consequently, as teachers, it is our responsibility to allow class time for such discussions and reflections, realizing that "destabilizing reigning ideas" will help classrooms to "elicit social debate" (Wiggins, 2011, p.10); though admittedly, this can only occur when lecturers willingly and actively lead a classroom into reflection, processing, debate, and questioning. Considering destabilizing factors that challenge truisms implies the educators themselves have critical thinking abilities to see beyond rigid dichotomies of morals. Furthermore, such a classroom practice implies lecturers relinquish control, allowing students to drive forth discussion with limited instruction, a practice potentially unfamiliar and/or uncomfortable for some educators.

Nevertheless, I would encourage us all to take a lesson from these writers and educators' advice regarding the issue of morals within the literature classroom. In full disclosure, I too am guilty of not requiring students to engage in further discussion and/or processing. I also have lacked critical thinking about morals in literature discussions. Rather than using students' truisms as a point of "take off" for class discussion, and meeting the students at their present position, by inviting them to engage and think critically about morals, I instead would listen patiently, only to hijack and reroute the discussion. I dismissed morals, demonstrating that I too was unable or unwilling to transcend the banal, mundane moral discussions. Likewise, I had mistakenly assumed the problem to be students on a die-hard quest to find clear-cut morals of the tale. I now realize more complex issues are at hand, and ones worthy of further study, as I believe they are crucial to how our EFL Indonesian students view literature.

In fact, future studies may explore cultural and educational factors that contribute to a limited moralizing view of literature. Creative literature lecturers may discover new methods that circumvent or challenge moralism in the classroom, or craft activities that encourage in-depth, rather than reductive, thinking. This issue is worthy of our attention, for if Indonesian EFL literature lecturers hope to foster critical thinking skills among their students they may first need to help them break free of their moral prison. We may do this by facilitating dialogue and allowing space to process and challenge moral assumptions, perhaps by first demonstrating that we are okay with ambiguity.

Thus, while important not to rule out morals as potentially educating, it is also crucial to recognize the potential harm of superficial moralizing discussions if lacking process of analysis (including questioning and critical thinking) and reflection. When we look towards regurgitating old elementary teachings, we not only waste time and bore students, but we may turn them off from literature, perhaps the most frightening possibility of all. In this way, we may inadvertently discourage students' reading and further growth. At the same time and equally depressing, educators may risk limiting ourselves from development and insights that interactive class discussion may reveal. Consequently, I would argue 
that when discussing and challenging cease, specifically regarding this issue of morals, it results in a lack of critical thinking and stagnancy in tertiary literature classes.

In closing, it is true that literature can be used "as a vehicle for contemplating the virtues" (Carroll, 2002, p. 19). However, the above analogy only functions properly if the vehicle is reliable. In this way, let us understand the vehicle to represent a piece of literature that yields well to critical ethical considerations and discussion. Likewise, let us consider the driver as alternating between students and teacher, both needing to seize the steering wheel and intentionally drive discussion to a new destination. While trips to new places may be scary, it is surely more fun and interesting than just spinning in circles of ceaseless, repetitive moralizing.

\section{REFERENCES}

Bonadanna, R. R. (1999). "Doing military ethics with war literature.” http://www.isme.tamu.edu/ JSCOPE99/Bonadanna99.html.

Carroll, N. (2002). The wheel of virtue: Art, literature, and moral knowledge. The Journal of Aesthetics and Art Criticism, 60(1), 3-26.
Crary, A. (2000). Does the study of literature belong within moral philosophy: Reflections in the light of Ryle's thought. Philosophical Investigations, 23(4), 315-350.

Cresswell, J. W. (2007). Qualitative inquiry and research design: Choosing among five approaches. Lincoln, Nebraska: Sage Publications.

Jenkins, B. C. (1997). Aristotle comes to the literature circle. Journal of Education, 179(3), 59-79.

Josselson, R. (2004). The hermeneutics of faith and the hermeneutics of suspicion. Narrative Inquiries, 14(1), 1-28.

Kirk, R. (1981). The moral imagination. Literature and Belief, 1, 37-49.

Marshall, C., \& Rossman, G. (2006). Designing qualitative research $\left(4^{\text {th }}\right.$ ed.). Thousand Oaks, California: Sage Publications.

Pantic, N. (2006). Moral education through literature. IPI, 38(2), 401-414.

Plato. (2008). The republic. (B. Jowett, Trans.) Retrieved from http://www.gutenberg.org/ ebooks/1497.

Taylor, D. (1995). The ethical implications of storytelling. Mars Hill Review, 3, 58-70.

Wiggins, A. (2011). Not teaching ethics: Let students learn ethics by experiencing ethical behavior through Socratic seminar. Kappan Magazine, 93(1), 33-35. 